Open Access

\title{
The impact of transfer payments on urban- rural income gap: based on fuzzy RD analysis of China's midwestern county data
}

Genqiang Lei, Xiaohong Huang ${ }^{*}$ and Penghui Xi

*Correspondence:
hxhxmu@163.com
School of Economics, Xiamen
University, Xiamen, China

* Correspondence: School of Economics, Xiamen University, Xiamen, China

\begin{abstract}
Background: China's long term Gini coefficient is higher than the international warning line and the urban-rural income gap is still serious, meanwhile the transfer payments targeted adjusting the income distribution are increasing in recent years, which indicate that we should examine the impact of current transfer payment system on income gap.

Methods: By choosing Develop-the-west Strategy that is a quasi-natural experiment and applying regression of discontinuity of location, using 1054 counties data of 15 provinces in Midwestern China from 2000 to 2007, we analyze the impact of transfer payments on urban-rural income gap in this paper.

Results: The results show that local government in western China paid more transfer payments than in the central region, however, the income gap between urban-rural residents in the western region increased by $20 \%$. The widening effects are robust in different bandwidth situation such as distance or latitude and longitude. Meanwhile, the mechanism analyses find that urban residents benefit more than rural residents from transfer payments.

Conclusions: Therefore, we believe that transfer payments should be more targeted to invest in rural areas, at the same time, the central government should rationalize the structure of transfer payments as soon as possible, and correct the urban bias and structure bias of local fiscal expenditure.
\end{abstract}

Keywords: Transfer payments, Urban-rural income gap, Regression of discontinuity

\section{Background}

Since the tax reform in 1994, the basic pattern with the revenue centralization and expenditure decentralization in the relationship between the central and local allocation gradually formed. Local government has undertaken the responsibility of providing most of public service in a local region. The transfer payment system that is also known as the fiscal transfer payment system or local transfer payment system from central to local has been established and gradually perfected. Because of the large difference between different financial local governments, the government in the poverty-stricken areas appeared to be inadequate and the ability to regulate the income gap is minimal, which heavily depends on the central transfer. The data from the ministry of finance show that the transfer payment from the central government to the local government in 2014 reaches 4.66 billion yuan. In 2015, it is expected to reach 5.1 billion yuan. ${ }^{1}$ Nevertheless, China's long-

(c) The Author(s). 2016 Open Access This article is distributed under the terms of the Creative Commons Attribution 4.0 International License (http://creativecommons.org/licenses/by/4.0/), which permits unrestricted use, distribution, and reproduction in any medium, provided you give appropriate credit to the original author(s) and the source, provide a link to the Creative Commons license, and indicate if changes were made. 
term Gini coefficient is higher than the international warning line with 0.4. The Gini coefficient of residents issued by the National Bureau of Statistics in 2014 is 0.469 , and the income gap between urban and rural areas is still serious, which indicates that on the one hand, the current income distribution in China still has a lot of convergence space. On the other hand, we should also examine the impact of the current transfer payment system on the income gap. At the beginning of the year of 2015, the State Council issued the "opinions on the reform and promotion of transfer payment system from central to local," which is committed to further improve the transfer payment system, especially to promote the interregional equalization of basic public services as the main target and to promote the sustained and healthy development of economy and society. Therefore, the research on the transfer payment's effect on the income gap between urban and rural areas has important theoretical and practical significance, which is related to the implementation of fiscal policy to promote the balanced development of regional economy and also is directly related with the prospect and future of China's economic growth.

The current literature in this area mainly takes the residents of metastatic income as the breakthrough point and analyzes the direct regulating function of transfer payment in income distribution (Wang and Caminada 2011; Albouy 2012; etc.). However, the transfer income contains not only the direct central subsidies but also the subsidies from local levels. In fact, the local governments rely heavily on the higher transfer payment. From the perspective of local government implementing the transfer payments purely, research on the role of income redistribution of higher levels could be focused on, but such studies are rare. The current literature can be divided into three categories: first is the research about transfer payment with the policy target on resident income. Meng (2013) evaluates the policy effect of "8-7 poverty assistance," estimates with the income of national poverty county as the breakpoint, and suggests that the poverty county farmers' income significantly increase by $38 \%$. From the perspective of poverty gap in county farmers, the poverty alleviation policy and poverty subsidies are still not effective (Yao and Wang 2009; Park and Wang 2010). Second is the research on the effect of transfer payment structure on regional income. $\mathrm{Lu}$ and Chen (2012) used the method of marginal revenue analysis and found that the general transfer payment subsidies benefit the poor area more while the failure of equitable distribution is possible in the marginal benefit distribution of special transfer payments. Third is the research on the effect of transfer payment on local government behavior. Wagener (2000) found externality existed in the implementation of central policy by local government through the theoretical model, which has an effect on policy implementation. He and Dong (2015) suggested that the transfer payment played an incentive effect on improving people's livelihood based on residents' happiness maximization to analyze the mechanism of transfer payment on expenditure behavior. Zeng and $\mathrm{Hu}$ (2009) theoretically analyzed the fiscal system in China and suggested that the central, provincial, and municipal government expenditure have urban bias, which makes the country and township governments with the financial difficulties have to take the responsibility of providing public goods and to strengthen the urban-rural income gap. Due to the asymmetric information, Yin and Zhu (2011) found that as a result of a government pursuing economic growth rate rather than the welfare of the residents, the public service-oriented government had financial expenditure bias deviating from the goal of construction. Important progress has been made in the current literature, and shortcomings still exist, 
such as first, the model design in the empirical analysis of the current related research still has the endogeneity problem of the urban and rural residents' income in the implementation of transfer payments. Due to the interference of other factors, the consistent estimates are difficult to be obtained, which reduces the credibility of conclusions and policy recommendations. Second is that the policy evaluation of transfer payment is focused on the poverty alleviation to farmers' income, which makes it necessary to verify the different effect of transfer payment on income gap between urban and rural areas. Third is that manipulation is possible in making the residents' income as the breakpoints, and it is necessary to verify the empirical results with the strong exogeneity of instrumental variables. Fourth is that the current literature about the urban and rural income gap is based on the national or provincial level; the county level is still to be further studied.

Therefore, as for the important endogeneity problem, this paper tries to use the most effective design in the quasi-natural experiments, which is also called the regression of discontinuity. In line with the assumption of the RD model, it can be more effective to deal with the impact of endogenous problems and can also improve the accuracy to deal with the impact of endogenous problems. It is still relatively rare to use the model to analyze the fiscal problems. This paper selects the execution variable that has the distance of RD function within the western geographic dividing line, which can capture the unobserved factors that are related to the western dividing line in a certain sense. More convincing county data can be used to analyze the regulation effect of transfer payment on urban-rural income gap. Empirical results show that China's transfer payment regulating the regional financial balance will expand the income gap between urban and rural areas. The mechanism analysis results show that the transfer payment has a significant promoting effect on the urban residents' income while having a minor effect on the rural residents' income. Whether the empirical conclusions that are obtained according to the regression of discontinuity in the middle and western regions are applicable to the effect of transfer payment on other regions is a further research. There is no effective empirical evidence or institutional differences to deny the applicability of this argument. The expending gap in the urban-rural income is not only the hidden trouble in our social stability but also the important academic content. The regression of discontinuity that has a focus on transfer payment can, to a certain extent, enrich the extents and methods in the field.

\section{The theoretical analysis of transfer payment's effect on income gap between urban and rural areas}

In the background of fiscal decentralization, the unequal rather than the scarcity is focused on. The regulation of income redistribution and the effective processing of competition between local governments are root in the appropriate intervention of central government, which forms the transfer payment (Oates 2005). As for the backward area, the state formally proposed the strategy of a large-scale development of the western region. The central government gradually increased the capital investment strength in the western region since 2000 . The accumulative financial center has transfer payments to the western region of 8.5 billion yuan, accounting for $40 \%$ of the total transfer payments over the same period. ${ }^{2}$ What the central government clearly put forward increased transfer payments, special grant funds, subsidies in ethnic minority areas, rural tax reform subsidies, and township financial difficulty subsidies on the western region, which aims to directly achieve gap convergence effect of regional development and residents' income. 
Theoretically, transfer payments are given to function of balancing regional financial resources and equalizing public services (Boadway and Shah 2007). However, after the tax system reform, the practical significance on the separation system is not formed. With the pressure of central financial centralization and local expenditure, as well as with the restriction of a household registration system in the long-term urban-rural dual structure, a population cannot fully flow, which makes the transfer payment of central to local governments as an important tool to ensure that the local residents enjoy basic public services. Thus, this paper uses the non-completely free-flowing fiscal decentralization model constructed by Wagener (2000) and Liu (2011). The difference is that we begin with the local government transferring for higher governments as the final executors and theoretically analyze the effect of local government behavior on the transfer payment's function of reducing urban and rural residents' income gap.

We assume that there are only central and local governments in one county. The transfer from central to local is $\mathrm{T}$, and the local government behavior directly affects the externalities of social production. The two regions $i$ are 1 and 2 . There are two groups $v$ in each region, which is represented by $u, r$. One is the rich group that possesses the fixed factor, namely, urban resident. The other is the floating workforce, namely, rural resident. The total number of the floating population is:

$$
\bar{L}_{r}=l_{r}^{1}+l_{r}^{2}
$$

We define the per transfer payment provided by the local government to group $V$ in the region $i$, then:

$$
\bar{T}^{i}=T_{u}^{i}+T_{r}^{i}
$$

In a simple market economy, the labor market is competitive. The production function of $f\left(l_{u}^{i}, l_{r}^{i}\right)$ is strictly concave. The marginal output is the level wage. Then the average income of rural residents and urban residents can be expressed as:

$$
\begin{aligned}
& I_{r}^{i}=f_{r}^{i}+T_{r}^{i} \mathrm{I}_{\mathrm{r}}^{\mathrm{i}}=\mathrm{f}_{\mathrm{r}}^{\mathrm{i}}+\mathrm{T}_{\mathrm{r}}^{\mathrm{i}} \\
& \mathrm{I}_{\mathrm{u}}^{\mathrm{i}}=\frac{\mathrm{f}\left(\mathrm{I}_{\mathrm{u}}^{\mathrm{i}}, \mathrm{I}_{\mathrm{r}}^{\mathrm{i}}\right)-\mathrm{f}_{\mathrm{r}}^{\mathrm{i}}+\mathrm{T}_{\mathrm{u}}^{\mathrm{i}} \cdot \mathrm{I}_{\mathrm{u}}^{\mathrm{i}}}{\mathrm{I}_{\mathrm{u}}^{\mathrm{i}}} I_{u}^{i}=\frac{f\left(l_{u}^{i}, l_{u}^{i}\right)-f_{r}^{i} \cdot l_{r}^{i}+T_{u}^{i} \cdot l_{u}^{i}}{l_{u}^{i}}
\end{aligned}
$$

With the situation of labor as free-flowing, the consumption will eventually reach a consensus.

$$
I_{r}^{1}=I_{r}^{2}
$$

According to functions (1) to (5), the change of transfer payment of local government leads to the changes of urban and rural income:

$$
\frac{\partial I_{r}^{i}}{\partial T_{r}^{i}}=f_{r r}^{i} \cdot \frac{\partial l_{r}^{i}}{\partial T_{r}^{i}}+1
$$




$$
\begin{gathered}
\frac{\partial l_{r}^{i}}{\partial T_{r}^{i}}=\frac{\partial l_{r}^{i}}{\partial T_{r}^{i}}=\frac{f_{u u}^{1}+f_{u u}^{2}}{\left(f_{u r}^{1}+f_{u r}^{2}\right)^{2}-\left(f_{u u}^{1}+f_{u u}^{2}\right)\left(f_{r r}^{1}+f_{r r}^{2}\right)} \frac{\partial \mathrm{I}_{\mathrm{r}}^{\mathrm{i}}}{\partial \mathrm{T}_{\mathrm{r}}^{\mathrm{i}}}=-\frac{\partial \mathrm{I}_{\mathrm{r}}^{\mathrm{j}}}{\partial \mathrm{T}_{\mathrm{r}}^{\mathrm{i}}} \\
=\frac{\mathrm{f}_{\mathrm{uu}}^{1}+\mathrm{f}_{\mathrm{uu}}{ }^{2}}{\left(\mathrm{f}_{\mathrm{ur}}^{1}=\mathrm{f}_{\mathrm{ur}}^{2}\right)^{2}-\left(\mathrm{f}_{\mathrm{uu}}^{1}+\mathrm{f}_{\mathrm{uu}}^{2}\right)\left(\mathrm{f}_{\mathrm{rr}}^{1}+\mathrm{f}_{\mathrm{rr}}^{2}\right)} \\
\frac{\partial l_{r}^{i}}{\partial T_{u}^{i}}=-\frac{\partial l_{r}^{i}}{\partial T_{u}^{i}}=-\frac{f_{u r}^{1}+f_{u r}{ }^{2}}{\left(f_{u r}^{1}+f_{u r}^{2}\right)^{2}-\left(f_{u u}^{1}+f_{u u}^{2}\right)\left(f_{r r}^{1}+f_{r r}^{2}\right)}
\end{gathered}
$$

According to Boadway (1982):

令 $D=-\left[\left(f_{u r}^{1}+f_{u r}^{2}\right)^{2}-\left(f_{u u}^{1}+f_{u u}^{2}\right)\left(f_{r r}^{1}+f_{r r}^{2}\right)\right]>0$

Then:

$$
\begin{aligned}
& \frac{\partial I_{r}^{i}}{\partial T_{r}^{i}}=1-\frac{1}{D}\left[f_{r r}^{i} \cdot\left(f_{u u}^{1}+f_{u u}^{2}\right)\right]=\frac{1}{D}\left[f_{r r}^{j} \cdot\left(f_{u u}^{1}+f_{u u}^{2}\right)\right] \\
& \frac{\partial I_{u}^{i}}{\partial T_{u}^{i}}=-f_{r r}^{i} \cdot \frac{\partial l_{r}^{i}}{\partial T_{u}^{i}} \cdot \frac{l_{r}^{i}}{l_{u}^{i}}=\frac{1}{D}\left[-f_{r r}^{i} \cdot\left(f_{u r}^{1}+f_{u r}^{2}\right) \cdot \frac{l_{r}^{i}}{l_{u}^{i}}\right]
\end{aligned}
$$

Equation 10 indicates that the rural residents can be possible benefitting from the transfer payments. But the size of benefits is related to the externality of local government behavior. Equation 11 indicates that the reaction of urban residents' income level on transfer payment also depends on the interaction between urban and rural areas. Therefore, it only needs to be compared the changing rates of transfer payment in rural and urban areas to reflect the income gap between these areas. We thus propose a hypothesis of this study that in the premise that the influence of another variable being controlled, if the reaction of urban on transfer payment is more sensitive than that of rural, then the local government's function of income redistribution and regulation may be influenced by the policy trade-offs, which widens the income gap phenomenon.

\section{Methods}

\section{Empirical model and data description}

\section{The empirical model}

Using OLS regression to analyze formula 12, the subscript $i$ represents the country and $t$ represents the year. Among them, transfer represents the transfer payments, and the estimates of $\phi$ represent the effect of transfer payment on urban-rural income gap. $X$ is the control variable, which controls the provinces and time effect. $\xi$ is the error term. However, the OLS regression still cannot accurately control the unobservable or unmeasured variable, such as geography resources, local customs and habits, consumption habits, culture, and religion, which is likely to affect the income level of local residents. Therefore, $\phi$ would inevitably overestimate or underestimate its effect on income gap between urban and rural areas.

$$
\text { Gap }_{i t}=\omega+\phi \text { Transfer }_{i t}+v X_{i t}+\mu_{i}+\eta_{t}+\xi_{i t}
$$

In order to overcome the endogeneity problem, referring to the idea of Almond et al. (2009) about the effect of heating influence with the sub-boundary of north and south 
on life value, this paper uses the fuzzy regression of discontinuity with the subboundary of Midwest ${ }^{3}$. FRD thinks the breakpoint is nondeterministic, which relies on the non-continuity of treatment probability of a performing variable. The execution variable is the location while the processing variable is whether the transfer payment can be enjoyed. However, the processing variable is not strictly dependent on the geographic location, which means the breakpoint changes of the transfer payment are not strictly determined by the western region. In the practical work, the western region of Hunan Province, Enshi area of Hubei Province, and Yanbian area of Jilin Province in the central province enjoy the western development policy as a western region. Therefore, geographical discontinuity can be regarded as the instrumental variables in the processing state, and 2SLS regression estimation can be used.

$$
\begin{aligned}
& \text { Transfer }_{\mathrm{it}}=\alpha+\beta \text { West }_{\mathrm{i}}+\delta \mathrm{F}(\text { distance })_{\mathrm{i}}+\gamma \mathrm{X}_{\mathrm{it}}+\mu_{\mathrm{i}}+\eta_{\mathrm{t}}+\varepsilon_{\mathrm{it}} \\
& \text { Infrastructure }_{i t}=\alpha_{1}+\beta_{1} \text { West }_{i}+\delta_{1} F(\text { dis tan ce })_{i}+\gamma_{1} X_{i t}+\mu_{i}+\eta_{t}+\varsigma_{i t} \\
& \operatorname{Tax}_{\mathrm{it}}=\alpha_{2}+\beta_{2} \text { West }_{\mathrm{i}}+\delta_{2} \mathrm{~F}(\text { distance })_{\mathrm{i}}+\gamma_{2} \mathrm{X}_{\mathrm{it}}+\mu_{\mathrm{i}}+\eta_{\mathrm{t}}+\psi_{\mathrm{it}} \\
& \text { Gap }_{\mathrm{it}}=\theta+\lambda \text { Transferhat }_{\mathrm{it}}+\pi \mathrm{F}(\text { distance })_{\mathrm{i}}+\mathrm{k} \mathrm{X}_{\mathrm{it}}+\mu_{\mathrm{i}}+\eta_{\mathrm{t}}+\zeta_{\mathrm{it}}
\end{aligned}
$$

The first stage regression equation is 13 and the second stage regression equation is 16. $\beta$ captures the discontinuity effect of central government's transfer payment on the western region. $\lambda$ represents the effect of transfer payment on income gap between rural and urban, which is the coefficient of the paper focused on. The sample we use in this paper is the adjacent county in the western geographic division line. The social and economic characteristics of countries and cities surrounding the boundary line are considered to be the same. Western counties are regarded as the processing group, which means the value of west is 1 while the central regions are regarded as the controlling group, which means the value of west is $0 . F$ (distance) represents the RD function form with the distance as executive variable, which can capture the relative unobserved factors in the boundary line of central and western boundaries in a sense. It is reflected as the function of controlling geographic location. Moreover, although the nonparametric statistic method does not depend on the specific function form, the data is required to actually reflect the actual geographic information of each observed value (Black 1999), and the model is required to be with a large number of observation samples close to the critical value (Imbens and Lemieux 2008). Due to the restriction of detailed data information, this paper refers to the relatively flexible semiparametric regression of discontinuity model suggested by Dell (2010). In order to ensure the robustness of empirical results, the form with different orders is used, and the individual characteristics that are not changing with time and the changing trend that is changing with time are controlled. At this time, the separated error term is independent with key variables. Moreover, with the premise hypothesis that the distribution of the controlled variable around the critical value is continuity, only the optimal bandwidth needs to be controlled. Whether other variables are controlled or not would have no greater impact on the regression results. However, the selection of optimal bandwidth can only be close to the critical values of an executive variable in the actual operation. Therefore, the controlled variable can be added in the regression to improve the estimation efficiency.

It needs to be explained that due to the majority and complexity of a western development policy, it not only involves the significant differences of transfer payment in the 
Midwest but also involves the capital investment, preferential tax policies, and other related industrial policies in western infrastructure construction ${ }^{4}$. In order to ensure these policies have no influence on the effect of transfer payment on income gap between urban and rural, it is necessary to verify whether the discontinuity points exist around the western boundary line in addition to the transfer payment. This paper summarizes the other two major variables in the western development strategy policy, namely, the interpreted variable of infrastructure construction funds. This paper uses a variable of per capital basic construction investment amount and an explanatory variable of tax preferential policies in Eq. 15. This paper uses the indicator of macro tax burden level.

\section{Data description}

The State Council issued the notice "the implementation views of policies and measures on great western development" and identified the region of western development: Chongqing, Sichuan, Guizhou, Yunnan, Tibet, Shanxi, Gansu, Qinghai, Ningxia, Xinjiang, Inner Mongolia, and Guangxi. The Midwest (excluding in Inner Mongolia, Xinjiang, Tibet ${ }^{5}$ ) in this paper contains 1054 counties in 15 provinces as the sample data.

Urban-rural income gap (Gap): According to the current literature, the urban and rural income in national or provincial and municipal levels should be represented with the ratio of per capital disposable income in urban and per capita net income in rural. However, the county-level data used in this paper is from "China Statistical Yearbook for Regional Economy" (2001-2008). This yearbook only covers the average wage income of workers in urban residents and residents' per capita net income. Although replacing the urban disposable income level with the wage income would be an overestimation, this paper studies the changing trend of income gap between urban and rural areas. The changing trend of income levels and disposable income levels is the same. Although there are deviations, it still illustrates the problem, which has some credibility to a certain extent. Moreover, in comparison with the ratio of average income in provincial town on-the-job workers and the net income in rural residents and the ratio of per capital disposable income in provincial urban residents and the net income in rural residents, we find that the correlation coefficient is 0.8226 , which is significant at $1 \%$ level. It has certain representativeness regarding the ratio of average wage income of on-the-job workers and the per capita net income in rural residents as the income gap between urban and rural areas.

Transfer: The data is from the "Financial Statistical Data in the National Counties" (2001-2007). ${ }^{6}$

The transfer payment used in this paper has eliminated the tax rebates and original system of subsidy ${ }^{7}$. This is because the transfer payment is to maintain the local vested interests before the tax reform, and higher income leads to more return funds and subsidies. Since the absolute amount of transfer payment cannot be directly compared, this paper selects the relative amount of transfer payment, which means that regarding the fiscal revenue (financial strength at the beginning of the period in each area) as the base to calculate the relative variation of transfer payment each year after 2000. Other control variables are from the "Social Economic Statistical Yearbook in Counties of China" and CEIC database, which have a more unified macro data statistics as shown in Table 1.

Note that with the central and western province boundary line as the discontinuity, the relative distance from the left of the boundary line is negative and the relative distance from the right of the boundary line is positive. The level of tax burden is 
Table 1 Statistical feature of the main variables

\begin{tabular}{lllllll}
\hline Variable name & Index & $\begin{array}{l}\text { Sample } \\
\text { number }\end{array}$ & Mean & $\begin{array}{l}\text { Standard } \\
\text { deviation }\end{array}$ & Minimum & Maximum \\
\hline $\begin{array}{l}\text { Income gap between urban and } \\
\text { rural areas }\end{array}$ & Gap & 6520 & 5.679404 & 2.810724 & 1.332908 & 23.24396 \\
Transfer payment & Transfer & 8053 & 4.772247 & 7.482760 & 0.047015 & 94.20853 \\
Western region or not & West & 8432 & 0.598672 & 0.490196 & 0 & 1 \\
Distance & Distance & 8432 & -1.234651 & 4.656160 & -16.25232 & 8.757799 \\
Per capital basic construction & Infrastructure & 8224 & 0.177283 & 0.317755 & 0.001079 & 5.454545 \\
investment(10,000 yuan/person) & Tax & 8051 & 0.041999 & 0.016694 & 0.017679 & 0.078604 \\
Tax burden level & Gdpper & 8340 & 0.577577 & 0.487237 & 0.050675 & 7.516575 \\
Per capital GDP(10,000 yuan/person) & Pindustry & 8238 & 0.320898 & 0.146475 & 0.005649 & 0.987018 \\
Proportion of the first industry & Sindustry & 8234 & 0.355314 & 0.167509 & 0.005645 & 0.986210 \\
Proportion of the second industry & Grper & 7981 & 0.024567 & 0.033896 & 0.001671 & 1.112006 \\
Per capita fiscal revenue(10,000 & & & & & & \\
yuan/person) & Urban & 8101 & 0.142832 & 0.094575 & 0 & 1 \\
Urbanization rate & Densitypop & 8253 & 0.026757 & 0.023495 & 0.000014 & 0.151786 \\
Population density & LnLoan & 8233 & 11.26259 & 1.038916 & 5.743003 & 13.99783 \\
$\begin{array}{l}\text { Balance of financial institutions loan } \\
\text { at the end of the year }\end{array}$ & & & & & & \\
Percentage of students in school & Students & 8254 & 0.059936 & 0.018160 & 0.000418 & 0.252336 \\
\hline
\end{tabular}

measured by the macro tax burden standard, which is represented by the ratio of local fiscal revenue and GDP. The urbanization rate is the ratio of non-agriculture population and total population. The balance of financial institutions loan at the end of the year is the natural logarithm of the ratio of balance of financial institutions loan at the end of the year and GDP. The proportion of students in the school is the ratio of elementary school students' number and the total population number.

\section{Results and discussion}

The regression results and analysis

The regression results of OLS

Table 2 shows the regression results of formula 12. The first column is the results of pooled OLS regression for the full sample. The variation of transfer payment expands

Table 2 Results of OLS regression

\begin{tabular}{|c|c|c|c|c|c|c|c|}
\hline Gap & (1) & (2) & (3) & (4) & (5) & (6) & (7) \\
\hline $\begin{array}{l}\text { Model and sample } \\
\text { range }\end{array}$ & $\begin{array}{l}\text { Mixed } \\
\text { regression }\end{array}$ & $\begin{array}{l}\text { Fixed } \\
\text { effect }\end{array}$ & $\begin{array}{l}\text { Less than } \\
200 \mathrm{~km}\end{array}$ & $\begin{array}{l}\text { Less than } \\
150 \mathrm{~km}\end{array}$ & $\begin{array}{l}\text { Less than } \\
125 \mathrm{~km}\end{array}$ & $\begin{array}{l}\text { Less than } \\
100 \mathrm{~km}\end{array}$ & $\begin{array}{l}\text { Less than } \\
75 \mathrm{~km}\end{array}$ \\
\hline Transfer & $\begin{array}{l}0.108^{* * *} \\
(0.00944)\end{array}$ & $\begin{array}{l}0.103^{* * *} \\
(0.0113)\end{array}$ & $\begin{array}{l}0.128^{* * *} \\
(0.0211)\end{array}$ & $\begin{array}{l}0.118^{* * *} \\
(0.0220)\end{array}$ & $\begin{array}{l}0.119^{* * *} \\
(0.0231)\end{array}$ & $\begin{array}{l}0.127^{* * *} \\
(0.0237)\end{array}$ & $\begin{array}{l}0.130^{* * *} \\
(0.0253)\end{array}$ \\
\hline$R^{2}$ & 0.461 & 0.611 & 0.546 & 0.536 & 0.526 & 0.546 & 0.557 \\
\hline Controls & Yes & Yes & Yes & Yes & Yes & Yes & Yes \\
\hline Province FE & No & Yes & Yes & Yes & Yes & Yes & Yes \\
\hline Year FE & No & Yes & Yes & Yes & Yes & Yes & Yes \\
\hline Observations & 5825 & 5825 & 1894 & 1480 & 1273 & 1048 & 850 \\
\hline
\end{tabular}

Note: The values in the brackets represent the standard deviation of cluster robust. The third and seventh columns are estimated by the two-way fixed effect with the local samples

*** represents the significant level at $1 \%$ 
the income gap between urban and rural areas for $10.8 \%$ with the significant level at $1 \%$. The second column represents the regression of two-way fixed effects with the coefficient $\phi$ of $10.3 \%$, which indicates the effect of transfer payment on urban-rural income gap is positive in the conditions at county-level clustering. In addition, from the perspective of a local sample, which is shown from the third column to the seventh column, we can see from the regression of the local sample that is around the western boundary line in the scope of $200 \mathrm{~km}$ to $75 \mathrm{~km}$ that the coefficient of transfer payment on urban-rural income gap is between 11 and 13\%, which has the pulling effect on income gap between urban and rural.

\section{Discontinuity regression}

This paper uses the function form of distance as the discontinuity regression results. For RD estimation, the graphic method is an important step to illustrate a problem and also an effective method to test whether the conditions can be met or not (Lee and Lemieux 2010). Samples are limited within the western boundary line of $150 \mathrm{~km}$, drawing the scatterplot of execution variables about the income gap between transfer payment and urbanrural income gap with the three items of distance as the RD function form, which is shown in Table 2. The top left image of Fig. 1 shows there is a discontinuity point at the western boundary line of critical value, which indicates that the transfer payment obtained in the western region is higher than that in the middle. The top left image of Fig. 1 shows the imbalance phenomenon that the income gap in the western region is higher than that in middle region. In addition, there is no obvious difference in the infrastructure construction fund investment and tax burden around the central and western boundary line, and the critical value of boundary line is continuous.

Figure 1 initially shows that the increasing transfer payment contributes to the improvement of the income gap between urban and rural areas. However, whether it has a negative effect or not depends on the model estimation. From Fig. 1, the three items of distance can better fit the distribution of scattered points and the three items of distance are used in the regression as the RD function form. At the same time, taking into account the need of selecting multiple bandwidths around the breakpoint, the regression results would not change along with the change of bandwidth. According to

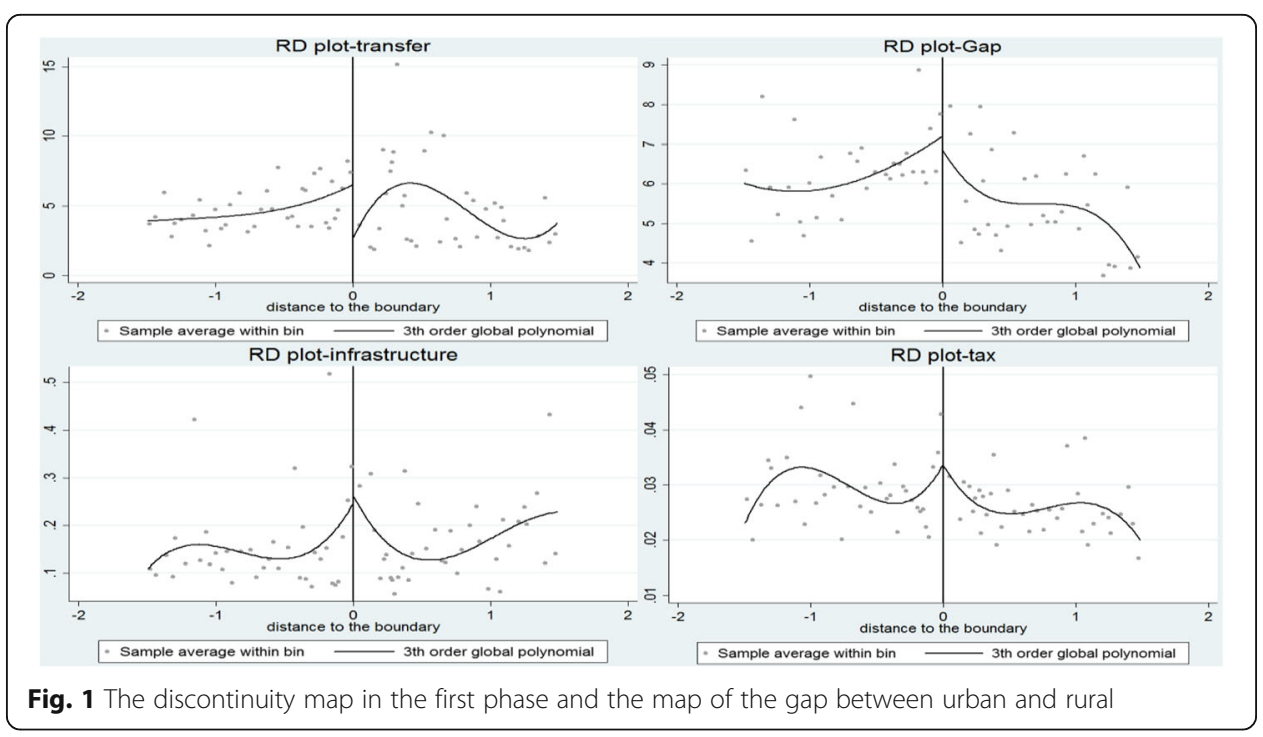


the calculation of optimal bandwidth proposed by Imbens and Kalyanaraman (2012), the optimal bandwidth is about $200 \mathrm{~km}$, and this paper selects the sample scope of 150, 125,100 , and $75 \mathrm{~km}$ for the local regression.

The result of the first stage regression is shown in Table 3, and the discontinuity effect of these three major polices is summarized. Taking into account the heteroskedasticity, this paper uses the county cluster robust standard errors, and all the models are controlled at the provincial level and time effect. Overall, only the transfer payment has the significant differences in the Midwest with the significant level of 5\%. The infrastructure fund investment and tax incentives in the central and western regions have no obvious discontinuity. Among them, the explanatory variable in panel 1 is transfer payment. The sample is in the scope of $200 \mathrm{~km}$ around the western border, and the regression coefficient $\beta$ is significantly positive at $1 \%$. Along with the shrinking bandwidth, even though the sample is limited to the range of $75 \mathrm{~km}$, the regression coefficient decreases but is significantly positive. The regression results show that the transfer payment counties around the Midwest boundary line have differences. The local government that is incorporated into the strategic policy of the western region can enjoy more financial capital injection. At the same time, from the regression results of panel 2, whether the sample is within $200 \mathrm{~km}$ or $75 \mathrm{~km}$, the infrastructure construction fund investments in the counties around the Midwest boundary line have no significant differences, which is due to the infrastructure invested by central government containing the transport channel connecting between the western region and its surroundings. Similarly, due to the fact the preferential tax treatment in the Midwest region is directly referred to the east region during the reform and opening up in a large

Table 3 Regression results of the first phase

\begin{tabular}{llllll}
\hline & $(1)$ & $(2)$ & $(3)$ & $(4)$ & $(5)$ \\
\hline $\begin{array}{l}\text { Sample } \\
\text { range }\end{array}$ & Less than & Less than & Less than & Less than & Less than \\
& $200 \mathrm{~km}$ & $150 \mathrm{~km}$ & $125 \mathrm{~km}$ & $100 \mathrm{~km}$ & $75 \mathrm{~km}$ \\
West & Panel 1:transfer & & & & \\
& $9.402^{* * *}$ & $9.271^{* * *}$ & $8.884^{* * *}$ & $8.472^{* * *}$ & $6.575^{* *}$ \\
$F$ (distance) & $(2.456)$ & $(2.450)$ & $(2.453)$ & $(2.478)$ & $(2.838)$ \\
$R^{2}$ & Cubic & Cubic & Cubic & Cubic & Cubic \\
Observations & 0.369 & 0.364 & 0.366 & 0.372 & 0.369 \\
& 2668 & 2113 & 1806 & 1482 & 1189 \\
West & Panel 2:infrastructure & & & \\
$F$ (distance) & 0.0372 & 0.0546 & 0.0222 & 0.0145 & 0.0662 \\
$R^{2}$ & $(0.0425)$ & $(0.0450)$ & $(0.0478)$ & $(0.0527)$ & $(0.0661)$ \\
Observations & Cubic & Cubic & Cubic & Cubic & Cubic \\
& 0.264 & 0.243 & 0.232 & 0.211 & 0.201 \\
West & 2675 & 2118 & 1813 & 1495 & 1208 \\
$F$ (distance) & Panel 3:tax & & & & \\
$R^{2}$ & 0.000752 & 0.000859 & 0.00113 & 0.000611 & -0.000468 \\
Observations & $(0.00398)$ & $(0.00404)$ & $(0.00456)$ & $(0.00503)$ & $(0.00708)$ \\
\hline Cubic & Cubic & Cubic & Cubic & Cubic \\
& 0.097 & 0.097 & 0.093 & 0.134 & 0.145 \\
& 2659 & 2110 & 1805 & 1485 & 1192 \\
\hline
\end{tabular}

Note: The value in the brackets represents the standard deviation of cluster robust, and the province effect and time effect are controlled

${ }^{* * *}$ and ${ }^{* *}$ represent the significant level at 1 and $5 \%$, respectively 
extent, the middle regions also enjoy a similar privilege. Therefore, the tax preferential policies in the Midwest region did not show a significant difference; panel 3 reflects the inference.

The regression results of the second stage are shown in Table 4. The first column limits the sample within the boundary line of $200 \mathrm{~km} / \mathrm{h}$. The coefficient is $23.4 \%$ with the significant level at $1 \%$ when the function of RD form is regressed. The coefficient decreases slightly when the quadratic distance is regressed with the value of $21.1 \%$ while the coefficient remains unchanged when the three terms of distance are regressed with the value of $21.1 \%$ at the significant level of $1 \%$. Along with the continued shrinking bandwidth, the coefficient is significant at the level of $1 \%$ when the sample is limited in the range of $75 \mathrm{~km}$ around the distance boundary line and is regressed with the low-order term. When regressed with a higher item, the significance of coefficient is declining but still significant at the level of $5 \%$. On the one hand, it is due to the sample being limited in a small scope as much as possible, and fewer observation points lead to the results not significant. On the other hand, when the distance is smaller and the fitting form is more close to the linear function form, the significance of the regression results with three or four terms of distance is declining. If the regression of an optimal bandwidth with $200 \mathrm{~km}$ calculated with the method of IK is regarded as the benchmark, it can be considered that $1 \%$ change in the transfer payment will lead to the widening gap between urban and rural income for 20 to $30 \%$, which indicates that the blindly increase of local government transfer payment cannot attain the intention of balance in urban and rural income. From Table 4, the sample is still large enough when the bandwidth is adjusted from 200 to $75 \mathrm{~km}$. The conclusion of this paper about the effect of transfer payment in the Midwest counties on the income gap between urban and rural areas is representative.

Table 4 Regression results with $F$ (distance)

\begin{tabular}{llllll}
\hline Gap & $(1)$ & $(2)$ & $(3)$ & $(4)$ & $(5)$ \\
\hline Sample range & Less than & Less than & Less than & Less than & Less than \\
Transfer & $200 \mathrm{~km}$ & $150 \mathrm{~km}$ & $125 \mathrm{~km}$ & $100 \mathrm{~km}$ & $75 \mathrm{~km}$ \\
& $0.234^{* * *}$ & $0.224^{* * *}$ & $0.219^{* * *}$ & $0.195^{* * *}$ & $0.198^{* * *}$ \\
$F$ (distance) & $(0.0491)$ & $(0.0489)$ & $(0.0497)$ & $(0.0477)$ & $(0.0536)$ \\
$R^{2}$ & Linear & Linear & Linear & Linear & Linear \\
Transfer & 0.413 & 0.401 & 0.395 & 0.444 & 0.430 \\
& $0.211^{* * *}$ & $0.208^{* * *}$ & $0.207^{* * *}$ & $0.192^{* * *}$ & $0.196^{* * *}$ \\
$F$ (distance) & $(0.0479)$ & $(0.0481)$ & $(0.0489)$ & $(0.0464)$ & $(0.0510)$ \\
$R^{2}$ & Quadratic & Quadratic & Quadratic & Quadratic & Quadratic \\
Transfer & 0.442 & 0.420 & 0.410 & 0.449 & 0.436 \\
$F$ (distance) & $0.211^{* * *}$ & $0.201^{* * *}$ & $0.216^{* * *}$ & $0.217^{* * *}$ & $0.253^{* *}$ \\
$R^{2}$ & $(0.0482)$ & $(0.0501)$ & $(0.0566)$ & $(0.0627)$ & $(0.0991)$ \\
Transfer & Cubic & Cubic & Cubic & Cubic & Cubic \\
$F$ (distance) & 0.442 & 0.425 & 0.404 & 0.434 & 0.373 \\
$R^{2}$ & $0.206^{* * *}$ & $0.201^{* * *}$ & $0.216^{* * *}$ & $0.231^{* * *}$ & $0.287^{* *}$ \\
Observations & $(0.0484)$ & $(0.0495)$ & $(0.0562)$ & $(0.0665)$ & $(0.116)$ \\
\hline Note & Quartic & Quartic & Quartic & Quartic & Quartic \\
& 0.446 & 0.426 & 0.405 & 0.425 & 0.322 \\
& 2043 & 1599 & 1371 & 1122 & 904 \\
\hline
\end{tabular}

Note: The same with Table 3 


\section{The robustness test}

First, in order to accurately reflect the geographical factors in different counties to control the differences in the Midwest, this paper regressed with the multi-discontinuity from the perspective of dual dimensions (the longitude and latitude difference with the Midwest boundary line), namely, the $F$ (distance) in formulas 13 and 16 is replaced by $F$ (longitude, latitude). Table 5 shows that the transfer payment has no effect on narrowing the income gap between urban and rural. The extent of expanding effect is the same with the regression results with the distance as the executive variable. Even if the observation point is reduced to the boundary line with $75 \mathrm{~km}$, the coefficient is significant at 1\% level, which is higher than that of the sample high away from the boundary line. This indicates that the expanding effect transfer payment on income gap between urban and rural has limited significance in the Midwest boundary line.

Second, in accordance with the design requirements of discontinuity regression model, the unobservable factors in the processing and control group are similar in principal. Therefore, joining the control variable or not has no effect on the final results. But in order to improve the efficiency of estimation, we add the control variable in Table 6 and compare the sensitivity of one-time addition method with the gradually adding method that refers to Altonji et al. (2005) and Dahlberg et al. (2008). The result has no difference with no adding variable, which indicates the effectiveness of instrumental variables ${ }^{8}$. When the observation distance is limited to the boundary line with $75 \mathrm{~km}$, the regression results are significant at the $1 \%$ level. Therefore, the regression results with the control variable verify the robustness of the results. In addition, the regression result is consistent when changing the sample. ${ }^{9}$

\section{Effectiveness test}

According to the validity of standard in Imbens and Lemieux (2008), the feasibility of RD regression in this paper is reflected in the following: (1) in the density continuity of execution variable, the sample used in this paper has no disadvantage. Since the observations around the boundary line can be mapped with clear position, this verifies the assumption rationality of geographic discontinuity regression, which is the characteristic of this model (Keele and Titiunik 2015). (2) In addition to the policy discontinuity, other effects change along with the geographical location. If the jumping occurs, the estimation results in the model also capture effect of other variables on the income gap between rural and urban. Other factors that influence the resident income contain the related controlling factors, the sample within $100 \mathrm{~km}$ around the Midwest boundary line, and the three items of boundary distance as the RD formula. From the regression

Table 5 Regression results with $F$ (longitude, latitude)

\begin{tabular}{llllll}
\hline Gap & $(1)$ & $(2)$ & $(3)$ & $(4)$ & $(5)$ \\
\hline Sample range & Less than & Less than & Less than & Less than & Less than \\
& $200 \mathrm{~km}$ & $150 \mathrm{~km}$ & $125 \mathrm{~km}$ & $100 \mathrm{~km}$ & $75 \mathrm{~km}$ \\
Transfer & $0.195^{* * *}$ & $0.187^{* * *}$ & $0.194^{* * *}$ & $0.189^{* * *}$ & $0.239^{* * *}$ \\
& $(0.0474)$ & $(0.0479)$ & $(0.0512)$ & $(0.0513)$ & $(0.0623)$ \\
$\begin{array}{l}F \text { (longitude, } \\
\text { latitude) }\end{array}$ & Cubic & Cubic & Cubic & Cubic & Cubic \\
$R^{2}$ & & & & 0.466 & 0.401 \\
Observations & 0.464 & 0.440 & 0.542 & 1122 & 904 \\
\hline
\end{tabular}

Note: The same with Table 3 
Table 6 Regression results when adding the controlled variable

\begin{tabular}{llllll}
\hline Gap & $(1)$ & $(2)$ & $(3)$ & $(4)$ & $(5)$ \\
\hline Sample range & Less than & Less than & Less than & Less than & Less than \\
& $200 \mathrm{~km}$ & $150 \mathrm{~km}$ & $125 \mathrm{~km}$ & $100 \mathrm{~km}$ & $75 \mathrm{~km}$ \\
Transfer & $0.159^{* * *}$ & $0.145^{* * *}$ & $0.155^{* * *}$ & $0.173^{* * *}$ & $0.189^{* * *}$ \\
& $(0.0448)$ & $(0.0458)$ & $(0.0489)$ & $(0.0510)$ & $(0.0617)$ \\
$F$ (distance) & Cubic & Cubic & Cubic & Cubic & Cubic \\
$R^{2}$ & 0.549 & 0.537 & 0.524 & 0.540 & 0.545 \\
Observations & 1894 & 1480 & 1273 & 1048 & 850 \\
Controls & Yes & Yes & Yes & Yes & Yes \\
\hline
\end{tabular}

Note: The same with Table 3

results in Table 7, the factors have no significant differences in the Midwest region, which verifies the effectiveness of conclusion in this paper,

Above all, this paper draws the conclusion that transfer payment contributes to the inequality of urban-rural income through the analysis of discontinuity regression of transfer payment on income gap between urban and rural. This paper acquires the consistent results of robustness check. In addition, the effective test results verify the feasibility of transfer payment on income gap between urban and rural.

\section{Analysis of mechanism}

Since the index of income gap between urban and rural is measured by the ratio of urban residents' wages and rural residents' net income, the above results show that the increasing relative transfer payment amount leads to the expanding of income gap between rural and urban for $20 \%$. Then how does the urban and rural residents' income change? In this regard, this paper takes the incremental income level of urban and rural residents' income as the explanatory variables. Results in Table 8 show that the coefficient of transfer payment on the incremental income of urban residents' income is significantly positive at the $5 \%$ level. Benefit of rural residents is small, and it is significant at the $10 \%$ level when the sample is within $75 \mathrm{~km}$ around the boundary line. On the basis of previous studies, this paper put forward the inherent mechanism of the influence; on the one hand, it is the tendency of local fiscal expenditure. The local fiscal expenditure tends to be invested in the urban areas with more sensitivity. In comparison with rural areas, urban areas benefit more in the transfer payment, which is the result of different systems in different regions. There are other scholars suggesting that the conclusion of fiscal expenditure has the characteristic of urbanization bias such as Lei and Cai (2012). On the other hand, with the asymmetric information, the structure of local

Table 7 Effectiveness test

\begin{tabular}{lllllllll}
\hline & $(1)$ & $(2)$ & $(3)$ & $(4)$ & $(5)$ & $(6)$ & $(7)$ & $(8)$ \\
\hline Explanatory variable & Gdpper & Pindustry & Sindustry & Urban & Students & Grper & LnLoan & Densitypop \\
West & -0.0212 & -0.0569 & 0.0633 & 0.0375 & -0.00258 & 0.00250 & 0.364 & -0.00259 \\
& $(0.0966)$ & $(0.0368)$ & $(0.0497)$ & $(0.0422)$ & $(0.00248)$ & $(0.00533)$ & $(0.279)$ & $(0.00360)$ \\
$F$ (distance) & Cubic & Cubic & Cubic & Cubic & Cubic & Cubic & Cubic & Cubic \\
$R^{2}$ & 0.291 & 0.398 & 0.212 & 0.122 & 0.382 & 0.176 & 0.229 & 0.126 \\
Observations & 1505 & 1556 & 1501 & 1437 & 1498 & 1472 & 1496 & 1496 \\
\hline
\end{tabular}

Note: The same with Table 3 
Table 8 Regression results of effect of transfer payment on income level of urban and rural residents

\begin{tabular}{|c|c|c|c|c|c|c|c|c|c|c|}
\hline \multirow[t]{2}{*}{ Explanatory variable } & \multicolumn{5}{|c|}{ The increment of income level of urban residents } & \multicolumn{5}{|c|}{ The increment of income level of rural residents } \\
\hline & (1) & (2) & (3) & (4) & (5) & (6) & (7) & (8) & (9) & (10) \\
\hline Sample range & $\begin{array}{l}\text { Less than } \\
200 \mathrm{~km}\end{array}$ & $\begin{array}{l}\text { Less than } \\
150 \mathrm{~km}\end{array}$ & $\begin{array}{l}\text { Less than } \\
125 \mathrm{~km}\end{array}$ & $\begin{array}{l}\text { Less than } \\
100 \mathrm{~km}\end{array}$ & $\begin{array}{l}\text { Less than } \\
75 \mathrm{~km}\end{array}$ & $\begin{array}{l}\text { Less than } \\
200 \mathrm{~km}\end{array}$ & $\begin{array}{l}\text { Less than } \\
150 \mathrm{~km}\end{array}$ & $\begin{array}{l}\text { Less than } \\
125 \mathrm{~km}\end{array}$ & $\begin{array}{l}\text { Less than } \\
100 \mathrm{~km}\end{array}$ & $\begin{array}{l}\text { Less than } \\
75 \mathrm{~km}\end{array}$ \\
\hline \multirow[t]{2}{*}{ Transfer } & $40.44^{* *}$ & $41.32^{* *}$ & $40.54^{* *}$ & $53.29^{* *}$ & $97.75^{* *}$ & 0.929 & 2.235 & 3.710 & $6.925^{*}$ & $14.82^{*}$ \\
\hline & $(17.42)$ & $(18.71)$ & $(18.58)$ & $(22.22)$ & $(48.40)$ & $(2.021)$ & $(2.230)$ & $(2.746)$ & $(3.746)$ & $(7.980)$ \\
\hline$F$ (distance) & Cubic & Cubic & Cubic & Cubic & Cubic & Cubic & Cubic & Cubic & Cubic & Cubic \\
\hline$R^{2}$ & 0.232 & 0.210 & 0.320 & 0.312 & 0.237 & 0.076 & 0.069 & 0.068 & 0.068 & 0.053 \\
\hline Observations & 2025 & 1591 & 1352 & 1091 & 874 & 1848 & 1448 & 1247 & 1035 & 829 \\
\hline
\end{tabular}


fiscal expenditure is biased. The rural areas that really need financial support do not enjoy the full benefits. The infrastructure is more backward and selfdevelopment is lower in the poorer areas. Only limited funds can be used to give priority to infrastructure and administration project, and there is fewer fiscal funds being used in the construction of people's livelihood project (Fu and Shen 2012). This explains the reason why the income level of rural residents has not been significantly improved to a certain extent.

Just as the theoretical model reflects, rural residents can benefit from the transfer payment, but its size has externality with government behavior. If the urban area is more sensitive to the transfer payment, local government may be weighted in the policy in order to expand the urban and rural income gap.

\section{Conclusions}

The geographic information is used in the local polynomial RD model to analyze the impact of transfer payment on urban-rural income gap. In comparison with other research, the executive variable of western geographic boundaries of distance, in a certain sense, captures the relative unobserved factors around the Midwest boundary line, effectively overcomes the endogeneity problem, greatly improves estimation accuracy of transfer payment effect on income gap, and examines the robustness of results and validity of model. The results show that transfer payment will expand the rural-urban income gap when regulating the equilibrium of regional finance. If most of the transfer payment continues to be used in an urban area or infrastructure by local government to make achievements in short time with neglecting the special care in peoples' livelihood project, then even the amount of transfer payment funds is huge, and narrowing the income gap between urban and rural would be of no avail. Therefore, in the process of transfer payment system reform and improvement, in addition to strictly implementing the "notices on reforming and improving the central's transfer payment to local government," according to the analysis results, policy suggestions are as follows: (1) empirical results show transfer payment has a significant expanding effect on rural-urban income gap. Central government should adjust the structure of transfer payment to gradually increase the general transfer payment and to improve the degree of freedom of local governments in addressing fiscal expenditure and at the same time integrating the special transfer payments with the principles of zero growth or little decrease. The increasing capital should show the rural tendency and focus on improving the rural residents of people's livelihood. The influence mechanism analysis shows that the expanding effect of transfer payment on ruralurban income gap is due to benefit of rural residents being less than that of urban residents. Therefore, it is important to constraint the local government behavior that implements policies of transfer payment. First, government function should change into "public service" and correct bias problem of fiscal expenditure structure. Second, a rural area should be paid attention in financial expenditure, especially in the construction of rural livelihood projects. It should be committed to promoting the equalization of public services in urban and rural areas and to effectively ease the problem of expanding income gap between rural and urban. (2) From a point of view, using efficiency and coverage of transfer payment by local government is to be improved. It is necessary to perfect the transfer payment system in a county and establish fiscal expenditure performance accountability. 


\section{Endnotes}

${ }^{1}$ Source: "Ministry of finance budget department: tax return from central to local and budget of transfer payment in 2015", Ministry of finance, March 24, 2015

${ }^{2}$ Source: liu Qiong: "The total transfer payment from central government financial to the west is 8.5 billion," Xinhua, October 22, 2013

${ }^{3}$ The regression model of discontinuity is one of the most advanced quasi-natural experiment designs in the empirical methods. It has been highly valued and applied in many fields, such as economics, political economics, education, biology, and behavior, but it is seldom used in the field of finance and taxation at present.

${ }^{4}$ Targeted measures are implemented by the central, which includes the inclined fiscal policy, financial development policies, preferential tax policies, natural resource policies, and public service policies. Related policies can be summarized into three categories: transfer payments, fund investment, and tax incentives, which promote the infrastructure construction. Among them, the funds in the financial development policy, resources industry, and public services policy that aim to promote west development are invested in infrastructure, which includes roads, railways, and water. The preferential tax policy is to promote the tax preferential policies of economic and social development, which involves income tax, value-added tax, tariff, farmland occupation tax, resource tax, and other taxes. For the tax incentives, the main beneficiaries are enterprise unit.

${ }^{5}$ The Mongolia Autonomous Region, as the western part of China, has only a small part that is adjacent with Shanxi Province, other parts are adjacent to Hebei Province. Therefore, excluding the small part of Mongolia has no much influence in comparing with the Midwest region. The data of Xinjiang and Tibet is missing and the characteristic of discontinuity regression model is the optimal estimation of local validity, which requires the sample to be controlled around the range of discontinuity and seeks the optimal bandwidth. Therefore, taking no consideration of these two regions has no much influence on the results.

${ }^{6}$ The statistic is compiled by the State Department of Ministry of Finance. The official statistics are only updated until 2009. Taking the consideration of the impact of financial budget system reform on the statistical caliber after 2007, this paper uses the data from 2000 to 2007.

${ }^{7}$ The transfer payment $=$ special subsidies + transfer payment subsides + transfer payment in ethnic areas + taxation expenses allowance in rural + transfer payment subsides in teachers of primary and secondary school + additional issuance of treasury bonds subsidiary + additional wage subsidies in arduous remote areas + settlement allowance + increase or reduce subsidies in the adjustment income assignment + other income + provincial grants to municipalities + other funds + other benefits

${ }^{8}$ Due to space limitation, only the results of the regression that adds the controlled variable are listed in Table 6. In the local sample, the regression results have no more changes when adding the economic level (per capital GDP, proportion of first industry, proportion of second industry), financial level (per capital revenue, macro tax burden level, infrastructure investment level), population level (urbanization rate population density), and proportion of balance of financial institutions loan and that of students in school.

${ }^{9}$ Due to space limitation, the author can provide if required. 
Authors' contributions

All authors read and approved the final manuscript.

\section{Competing interests}

The authors declare that they have no competing interests.

Received: 21 September 2016 Accepted: 26 October 2016

Published online: 30 November 2016

\section{References}

Albouy D (2012) Evaluating the efficiency and equity of federal fiscal equalization. J Public Econ 96(9-10):824-839

Almond D, Chen Y, Greenstone M, Li H (2009) Winter heating or clean air? Unintended impacts of China's Huai river policy. Am Econ Rev 99(2):184-190

Altonji J, Elder T, Taber C (2005) Selection on observed and unobserved: assessing the effectiveness of catholic schools. J Polit Econ 113(2):151-184

Black SE (1999) Do better schools matter? Parental valuation of elementary education. Q J Econ 114(2):577-599

Boadway R (1982) On the method of taxation and the provision of local public goods: comment. Am Econ Rev 72(4): $846-851$

Boadway R, Shah A (2007) Intergovernmental fiscal transfers principles and practice. World Bank Publications, US

Dahlberg M, Mörk E, Rattsø J, Ågren H (2008) Using a discontinuous grant rule to identify the effect of grants on local taxes and spending. J Public Econ 92(12):2320-2335

Dell M (2010) The persistent effects of Peru's mining mita. Econometrica 78(6):1863-1903

Fu W I, Shen KR (2012) The equalization of transfer payment and local fiscal expenditure structure. Economic Research Journal (jingji Yanjiu) 47(5):45-57

He Q, Dong ZY (2015) Transfer payment, local fiscal expenditure and residents' happiness. Economic Perspectives (Jingjixue Dongtai) 2:56-65

Imbens GW, Kalyanaraman K (2012) Optimal bandwidth choice for the regression discontinuity estimator. Review of Economic Studies 79(3):933-959

Imbens GW, Lemieux T (2008) Regression discontinuity designs: a guide to practice. J Econ 142(2):615-635

Keele L. J, \& Titiunik R (2015) Geographic boundaries as regression discontinuities. Political Analysis, 14(1),265-7.

Lee DS, Lemieux T (2010) Regression discontinuity designs in economics. J Econ Lit 48(2):281-355

Lei GQ, Cai X (2012) Distortion of initial allocation, urban bias of fiscal expenditure and income gap between urban and rural - from the empirical evidence of provincial panel date in China. J Quan Tech Econ 29(3):76-89

Liu QZ (2011) Income inequality and the decomposition of the redistribution function between central finance and local finance. Finance Trade Econ 5:18-23

Lu HY, Chen SX (2012) Who benefits from the added transfer payment-based on the empirical analysis of China's county-level data. Finance Trade Econ 4:24-32

Meng LS (2013) Evaluating China's poverty alleviation program: a regression discontinuity approach. J Public Econ 101(1):1-11

Oates WE (2005) Towards a second generation theory of fiscal federalism. Int Tax Public Finance 12(4):349-373

Park A, Wang S (2010) Community-based development and poverty alleviation: an evaluation of China's poor village investment program. J Public Econ 94(7856):790-799

Wagener A (2000) Variable population size issues in models of decentralized income redistribution. Reg Sci Urban Econ 30(6):609-625

Wang C, Caminada K (2011) Disentangling income inequality and the redistributive effect of social transfers and taxes in 36 LIS countries. Dep Econ Res Memo 4:1-53

Yao HX, Wang XY (2009) Labor flow, education level, poverty alleviation policy and income gap in rural—based on the micro empirical research of multinomial logit model. Manage World 9:80-90

Yin H, Zhu H (2011) Expenditure bias research on county level production. Soc Sci China 1:88-101

Zeng G, Hu JJ (2009) Financial system of China's urban bias and income gap between urban and rural residents. Public Finance Res 2:36-39

\section{Submit your manuscript to a SpringerOpen ${ }^{\circ}$ journal and benefit from:}

- Convenient online submission

- Rigorous peer review

- Immediate publication on acceptance

Open access: articles freely available online

- High visibility within the field

- Retaining the copyright to your article 